\title{
FIELD INVESTIGATION AND ASSESSMENT ON THE WEAR OF ASPHALT PAVEMENT MILLING MACHINE PICKS
}

\author{
Henrikas SIVILEVIČIUS, Mindaugas MARTIŠIUS ${ }^{*}$ \\ Dept of Mobile Machinery and Railway Transport, Vilnius Gediminas Technical University, Lithuania
}

Submitted 21 May 2020; resubmitted 17 February 2021, 18 May 2021; accepted 14 June 2021

\begin{abstract}
Deteriorated asphalt pavement material is recycled applying proved technologies based on scientific principles and practical experience. The asphalt pavement layer during rehabilitation process is loosened by a mobile transport machine fracturing into the required material grading and called Reclaimed Asphalt Pavement (RAP). RAP is extracted while cutting asphalt chip in required depth at optimal speed by mean of changeable picks installed in a toolholder of milling machine rotating drum. During interaction with the asphalt pavement to be demolished, the wear of picks appears, and the dimensions of their elements decrease. Methodology and results of a field experimental research allowed statistically to determine and evaluate the wear dynamics of picks from 2 manufacturers are provided in this paper. The results provide that length of pick, diameter of carbide tip and diameter of steel body of picks from these manufacturers were decreasing proportionally to milled asphalt pavement surface. Applying the Fisher's criterion it was found that the variances of the reduction of these geometrical parameters are the same and they satisfy the normal distribution according to the Kolmogorov's criterion. All values of Student's criterion calculated statistics were higher than the critical values, which indicated that the wear intensiveness of the picks of the 2 manufacturers differed significantly. These data can be used to select suitable picks for the milling machine according to their wear intensity.
\end{abstract}

Keywords: asphalt recycling, reclaimed asphalt pavement (RAP), milling machine, pick wear, field investigation, statistical analysis.

\section{Notations}

GP - geometric parameter;

RAP - reclaimed asphalt pavement; RHMA - recycled hot mix asphalt.

\section{Introduction}

Transport infrastructure research plays an important role in transportation engineering science. Road transport infrastructure is continuously improved constructing asphalt pavement with the necessary performance and reliable as well as long life cycle. Asphalt pavement is one of the most important, complex and expensive elements of roads and streets. Once constructed, asphalt pavement needs to be maintained, repaired and/or recycled at the end of its life cycle. Recycling is the running trend through all over the world (Harun-Or-Rashid et al. 2018).

Asphalt pavement wears, deforms and is exposed under transport vehicles load, weather and climate conditions factors and influence of operational materials (Mea- gher et al. 2012; Ceylan et al. 2011; Akbarian et al. 2012; Ma et al. 2012; Kubo et al. 2016). Climatic parameters such as temperature and precipitation are the most important environmental factors that have considerable effects on the pavement distress (Khattak et al. 2014; Solatifar et al. 2017). The destructive influence of these factors also depends on the properties of the asphalt pavement and base layers, the hydrothermal regime of the road pavement structure (Solatifar et al. 2018). The ground water level rose rapidly ofter the drainage system was clogged (Salour, Erlingsson 2013). Cracking and rutting of road asphalt pavements are the 2 most critical types of distresses that govern overall pavement condition (Anyala et al. 2014). The presence of water flow on road surfaces may lead to early deterioration of bituminous pavements (Amini, Tehrani 2014). As the service period of the asphalt pavement increases, the collapse degree rises accordingly (Mansourkhaki et al. 2015; Farhan, Fwa 2009). In the event of visible damages of the wearing course of the road

${ }^{*}$ Corresponding author. E-mail: m.martisius@gmail.com 
surface, it is constantly repaired in order to improve the traffic conditions of vehicles and increase the service life (durability) of the road surface (Zofka et al. 2014).

The properties of bituminous binder are the most changed in old asphalt pavement due to aging process (Liu et al. 2014; Kleizienè et al. 2019). Aging refers to the change in the binder structure and/or composition due to influence of temperature and oxygen. This change makes the binder harder and more brittle. Aging is caused by different mechanisms, such as volatilization of hydrocarbon elements at high temperatures, and breaking of intermolecular bonds to from new molecular structures, and oxidation (Papagiannakis, Masad 2008). Oxygen diffusion and oxidative reaction are 2 main factors in asphalt oxidative aging discovered by experiment, but the dynamic balance between them could not be easily studied by experimental methods due to its comprehensiveness. A pavement oxidation was utilized to simulate this process in asphalt: oxygen molecules penetrate into the asphalt film and then react with the asphalt molecules (Cui et al. 2018). When the failure rate increases to the critical state of the pavement and its local repair is irrational, the upper (wearing), lower (binder) and/or base layers of the asphalt pavement are recycled. Re-use of asphalt pavement materials (recycling) creates ability to save new (virgin) minerals and bituminous binder as well as improving environmental protection.

RAP is typically generated through 2 reclamation procedures: milling and full-depth removal. Special machines, with a rotating drum holding cutting teeth, can "mill" a specific depth from the existing pavement without disturbing the base layers or subbase of the pavement (NAPA 1996)

Prominent among the concerns of the pavement construction industry, and funding agencies everywhere, are the conservation of materials, protection of the environment, and economy of construction/rehabilitation procedures. Pavement recycling with asphalt is a procedure that eminently and realistically meets these concerns, especially since it is economical of energy, materials and money (AI 1986).

Asphalt pavement layers are recycled using known technologies in the cold state at ambient air temperature (cold recycling) or in the hot state by heating it to high temperature (hot recycling). They can be recycled in place or recycled in plant. The asphalt pavement is mechanically broken into grains applying any technology. The old asphalt pavement in the cold state is broken apart by a mobile asphalt milling machine, which main working tool is a cylindrical drum with pick toolholders where are installed changeable picks, consisting of their own elements with a specific purpose. A milling machine at a set rational speed breaks up the asphalt layer at the required depth, and its grains are loaded into the truck or wheel loader bucket by a belt conveyor. The temperature of asphalt pavement has a large influence on the cutting resistance especially for asphalts with high content of bitumen and the energy consumption of asphalt milling process greatly depends on the amount of stone portion, bitumen content and the temperature (Furmanov et al. 2019).

The picks as cutting tools are ripping an asphalt pavement into small grain size material during the milling process. Pick quality has a huge influence on the milling performance, milling result and milling costs. During the milling process the tip of wolfram carbide pick undergoes intense usage through high pressure abrasion and the rough contact with the particles of asphalt mixture (Iovanas, Dumitrascu 2017). Pick inclination is utilised with the aim of achieving low cutter surface load (Toh 2005). Cutting loads on the asphalt milling machine were analysed by $\mathrm{Gu}$ et al. (2012).

Milled or crushed in a crusher and classified old asphalt pavement, i.e., RAP, can be used in the cold state with or without a binder to install the base road course (Plati, Cliatt 2019) or to produce RHMA. Asphalt hot recycling in-plant is the most commonly used method to maximize the economic benefits of rational re-use of asphalt paving materials (Vislavičius, Sivilevičius 2013; Zaumanis et al. 2014a, 2014b). During application of this technology, the old asphalt pavement or only its wearing course is dismantled by milling or breaking, followed by crushing and classifying grains into fractions.

Principles of asphalt pavement recycling (Sivilevičius et al. 2017) indicates, that it should be formed into small (maximum size from 22 to $32 \mathrm{~mm}$ ) RAP particles (Nguyen 2013), which heated in an asphalt mixing plant, decompose into individual unbound particles covered with old bitumen films (Zhang et al. 2019; Hossain et al. 2015). When they interact with the dosed rejuvenator, the viscosity of the old bitumen is reduced during the mechanical and diffusive mixing process and its other properties are restored to those suitable for repetitive use in the recycled asphalt mix (Wang et al. 2019; Ržek et al. 2020; Shirodkar et al. 2011; Zaumanis et al. 2014a, 2014b, 2019, 2020).

In countries with a sustainable economy, the relative use of RAP is steadily increasing, as asphalt pavements constructed several decades ago does not meet their requirements. The recovery volumes of old RAP are increased by increasing the percentage of RAP in the reclaimed asphalt mix. The maximum possible to add amount of RAP in RHMA mixture depends on the homogeneity of the RAP and the capacity of the asphalt recycling plants as well as plant design and adapted technologies (NCHRP 2011; Sivilevičius, Vislavičius 2019)

Road construction companies carrying out asphalt pavement recycling works must ensure the high quality of the recycled new asphalt layer, usually not inferior to the asphalt mixture made from new materials (Wu et al. 2007; Puccini et al. 2019). They also seek economic benefits by reducing the cost of work performance, reducing environmental pollution at all stages of the recycling process.

In the initial phase of asphalt pavement recycling process, its old layer is broken down to a certain size grain (RAP granulate). It is beneficial for the company to use slowly wearing picks in the milling machine. Whether picks manufactured by individual companies have the 
same durability can be determined by experimental tests carried out in the field or in the laboratory.

The aim of this paper is to present a model for determination the rate of wear of mobile asphalt milling machines picks by cold milling of asphalt pavement and apply it using field experimental data to evaluate the durability of picks of different manufacturers.

\section{Wear rate model of pick}

A road construction company removing an old asphalt pavement strives for economic efficiency in its operations. Economic efficiency, defined as the ratio of success achieved to the invested means, is depended on numerous factors, even for complex construction machinery. The cutting technology, and especially the pick, is of central importance (Wirtgen Group 2016).

Cold asphalt pavement milling is the core factor to keep the best possible road surface quality. Last 45 years after Wirtgen Group had introduced rotary cold asphalt milling technology in the road repair, quantities of RAP starting to grow each year. Asphalt pavement cold milling process has a beginning using carbide tools and this idea came from mining industry (Wirtgen Group 2019).

All elements of a pick are subjected to more or less wear depending on the material to be milled. In case of excessive fatigue on one of the components, e.g. the carbide tip, the steel body, the wear plate and/or the clamping sleeve, the pick should be replaced to pavement or reduce consequential damage to the more expensive toolholders system, with is also more complex to replace.

Independent on manufacturer there are several factors influencing on the milling costs (Table 1).

For example, the pricing of steel, carbide, manganese and oil influencing on the picks pricing, so picks price could vary several times a year. The price of investigated picks type price averagely was varied from 3.2 to 3.6 EUR in period from year 2018 to 2020 . According to the longterm experience there is known that for 1 ton of milled asphalt from 0.15 to 0.5 pick is used. This is an average norm, which varies depending on the properties of the asphalt pavement such as composition, strength, temperature, as well as weather conditions (temperature and water content). By selecting the milling depth, the force acting on the pick is set at the same time, and the milling speed determines the dynamics of this load. The linear speed of rotation of the milling drum with picks is constant and depends on a milling machine design. There is no single criterion or defined period of time when the picks needed to be changed in common practical experience. Practical recommendations for the operators are regular maintenances of the milling machine, its drum, the pick holders, the picks themselves and the water spray system. Maintenance must be performed by checking all parts mentioned above condition several times a day. Milling machine operator has to be enough qualified and act strictly according to operational manual recommendations. 3 main objectives are set for the milling process effective performance: optimum milling capacity, minimum the wear and tear and required RAP gradation curve.

The wear intensiveness (dynamics) model of the picks (Figure 1) presents that all their GP consistently decrease with increasing area of the asphalt pavement milled by the milling machine. In addition, the wear rate of individual picks of the 1st or 2nd investigated manufacturer installed in the milling drum may differ due to the stochastic nature of the disassembly conditions and the properties (quality) of the picks. Therefore, the variation of the GP reduction of the picks is indicated by the standard deviation $\sigma_{1}$ or $\sigma_{2}$. Assuming that the picks of the 2 manufacturers tends to wear differently, its correctness or erroneousness is proved by the methods of mathematical statistics.

The null hypothesis is tested $H_{0}$, stating that there is no significant difference in the statistics of the parameters of the 2 comparative sets. Known statistical criteria are used for this, i.e., rules for accepting or rejecting certain statistical hypotheses on the basis of experimental data from samples.

We are checking according Student's criterion if different manufacturers picks GP (dimensions) reduction due to wear general means $\Delta \bar{y}_{1}$ and $\Delta \bar{y}_{2}$ are statistically identical or different during asphalt pavement loosening process. Forasmuch as the GP means and variances $\sigma_{1}^{2}$ and

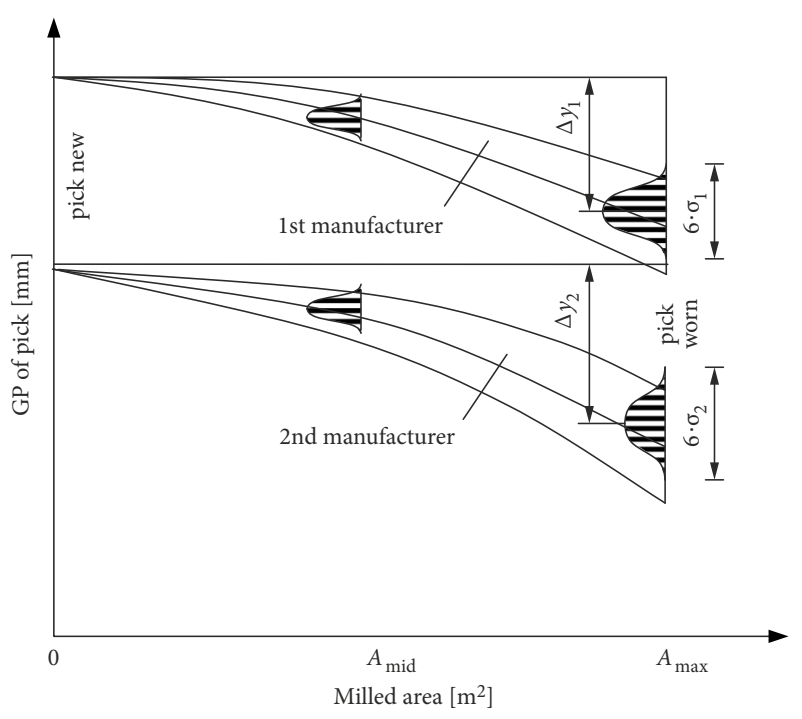

Figure 1. Wear model of asphalt milling machine picks from 2 manufacturers

Table 1. Factors influencing the costs of milling

\begin{tabular}{|c|c|c|c|c|c|}
\hline \multicolumn{9}{|c|}{ Main factors influencing the costs of milling } \\
\hline $\begin{array}{c}\text { Picks' } \\
\text { price }\end{array}$ & $\begin{array}{c}\text { Asphalt pavement } \\
\text { properties }\end{array}$ & $\begin{array}{c}\text { Weather } \\
\text { conditions }\end{array}$ & $\begin{array}{c}\text { Milling depth and } \\
\text { speed }\end{array}$ & $\begin{array}{c}\text { Milling machine characteristics and } \\
\text { technical condition }\end{array}$ & $\begin{array}{c}\text { Personnel } \\
\text { qualification }\end{array}$ \\
\hline
\end{tabular}


$\sigma_{2}^{2}$ of the picks of both manufacturers are known and the variances are taken equal (this assumption is verified using Fisher's criterion), the samples are independent and correspond to the normal distribution, the hypothesis of their uniform wear rate is calculated applying Student's $t$-statistic according to the equation:

$$
\begin{aligned}
& t_{c a}=\frac{\left|\Delta \bar{y}_{1}-\Delta \bar{y}_{2}\right|}{\sqrt{\left(n_{1}-1\right) \cdot \sigma_{1}^{2}+\left(n_{2}-1\right) \cdot \sigma_{2}^{2}}} \times \\
& \sqrt{\frac{n_{1} \cdot n_{2} \cdot\left(n_{1}+n_{2}-2\right)}{n_{1}+n_{2}}}
\end{aligned}
$$

where: $n_{1}, n_{2}$ - the number of picks of the 1 st and 2 nd manufacturers, respectively, excluding outliers, i.e., broken, fallen and/or unacceptably worn picks, which were replaced during the experiment with new ones not measured in the further study.

The degree of wear of the picks of the asphalt milling machine after the milling of asphalt pavement area $A$ is calculated by the equation:

$$
\Delta \bar{y}=\bar{y}_{\text {new }}-\bar{y}_{\text {worn }} \text {, }
$$

where: $\bar{y}_{\text {new }}$ - new picks GP arithmetic mean [mm]; $\bar{y}_{\text {worn }}$ - worn picks GP arithmetic mean [mm].

Whether the general variances $\sigma_{1}^{2}$ and $\sigma_{2}^{2}$ of the GP of the 2 manufacturers' picks are the same, they are checked applying the Fisher's criterion. The null hypothesis $H_{0}$ : $\sigma_{1}^{2}=\sigma_{2}^{2}$ is tested accepting the level of significances $\alpha$. The criterion for verification of this hypothesis is based on the statistics $F_{c a}$, which indicates the difference in variance expressed as a ratio:

$$
F_{c a}=F_{n_{1}, n_{2}}=\frac{\sigma_{1}^{2}}{\sigma_{2}^{2}}=\frac{\sigma_{\max }^{2}}{\sigma_{\min }^{2}},
$$

where: $\sigma_{\max }^{2}-$ large variance $\left[\mathrm{mm}^{2}\right] ; \sigma_{\min }^{2}-$ small variance $\left[\mathrm{mm}^{2}\right]$.

If null hypothesis $H_{0}$ : is correct, and statistics $F_{c a}$ are distributed according Fisher's $F$ law with $n_{1}-1$ and $n_{2}-1$ degrees of freedom, then $F_{c a}$ is smaller than its critical value $F_{c r}=F_{\alpha, n_{1}-1, n_{2}-1}$ and indicates that picks GP variances are not significantly different. This conclusion allows to compare the arithmetic means of the GPs of the picks according to Student's criterion, calculating $t_{c a}$ statistics according to Equation (1).

To confirm the null hypothesis of Fisher's criterion and Student's criterion, the sets from which samples were taken must be distributed according to the normal law. GP distribution of everyone wearing pick is checked if it conforms to the normal distribution. In practice, in addition to the skewness, kurtosis or Pearson chi-square criterion $\chi^{2}$, the Kolmogorov's criterion $(K(l))$ is often used, in which the discrepancy between the theoretical and empirical distributions is determined by calculating the maximum difference between the empirical distribution function $F_{n}(x)$ and the corresponding theoretical distribution function $F(x)$ :

$$
D=\max \left|F_{n}(x)-F(x)\right|,
$$

are so-called Kolmogorov's criterion statistics.

The empirical distribution function $F_{n}(x)$ and the implied (assumption) theoretical function of the normal distribution $F(x)$ are formed from the research data. The discrepancy between the theoretical and empirical distributions $D$ according to Equation (4) is determined and Kolmogorov's statistics are calculated:

$$
\lambda=D \cdot \sqrt{n} .
$$

When the value of $\lambda$ in the calculation is greater than its critical value $\lambda_{\alpha}$ determined by the selected significance level $\alpha$, then the null hypothesis $H_{0}$ that the random variable $Y$ (pick's GP) is distributed according to the normal distribution is rejected. Vice versa $\left(\lambda<\lambda_{\alpha}\right)$ - this hypothesis is accepted and indicates that the empirical data correspond to the normal distribution. Taking the recommended very strict significance level $\alpha=0.30$, the critical value of Kolmogorov's statistics is $\lambda_{0.30}=0.974$. Taking the usual level of significance $-\alpha=0.05, \lambda_{0.05}=1.358$ (Kremer 2012).

After the certain asphalt pavement area was milled out the GP relative decrease of picks wear is calculated according the equation:

$$
\varepsilon=\frac{\bar{y}_{\text {new }}-\bar{y}_{\text {worn }}}{\bar{y}_{\text {new }}} \cdot 100 \%=\frac{\Delta \bar{y}}{\bar{y}_{\text {new }}} \cdot 100 \% .
$$

Some manufacturers provide a value $C$ for the reduction of the pick length $L$ at optimum wear (Figure 2a). The pick usage for road milling machines wear path (dimension C) differs from $9.7 \mathrm{~mm}$ to $19.8 \mathrm{~mm}$, then $L$ from 88 to $89.5 \mathrm{~mm}$ (Wirtgen Group 2016).

\section{Methodology of experimental research}

WIRTGEN W1000 asphalt milling machine was selected for the study with a $1000 \mathrm{~mm}$ width cylindrical milling drum with spirally 80 picks installed in toolholders. The old remaining picks were removed from the milling drum before the pick wear test. In empty and cleaned toolholders (with insignificant wear) new picks of 2 manufacturers were installed: marked as $\mathrm{W}$ pick designation and marked as $\mathrm{K}$. A total of 40 picks W (odd numbers) and 40 picks $\mathrm{K}$ manufacturer (even numbers) were installed. All picks were measured with a calliper (Figure 3 ) to determine the 3 GPs of each prior to their installation.

The pick's length from carbide tip point to wear plate, which was shifted by the steel body towards the carbide tip, i.e., to the future position of the pick (value $l_{p}$ ) when it would be installed in the toolholder (Figure 2a).

Not the entire length $L$ of the pick, but the length up to the wear plate $l_{p}$ was measured because it was very difficult or impossible to measure the length $L$ of the pick already installed in the toolholder without retracting it out.

The diameter of the carbide tip of a new pick of each manufacturer ( $\mathrm{W}$ and $\mathrm{K}$ ) at its brazing location (maximum diameter) (value $d_{c t}$ ) was also measured. The 3rd di- 
mension of the pick was the diameter $d_{s b}$ of the steel body, which was measured through its middle, i.e., at a distance $h_{f}$ from the wear plate 4 (Figure 2a). The diameters $d_{c t}$ and $d_{s b}$ were measured twice in a direction perpendicular to the axis of the pick. When the diameter of the pick was measured for the 1st time, it was rotated in $90^{\circ}$ angle and was measured the 2 nd time. The data were registered in a $\log$ and the average values of the 2 measurements were calculated.

An old single-course asphalt concrete pavement was paved over a compacted base layer of unbound gravel and sand mixture. The asphalt concrete layer was constructed more than 30 years ago and so-called "alligator's skin" cracks were formed due to the aging of the bitumen, exposure to frost and fatigue. The surface was peeled in

a)
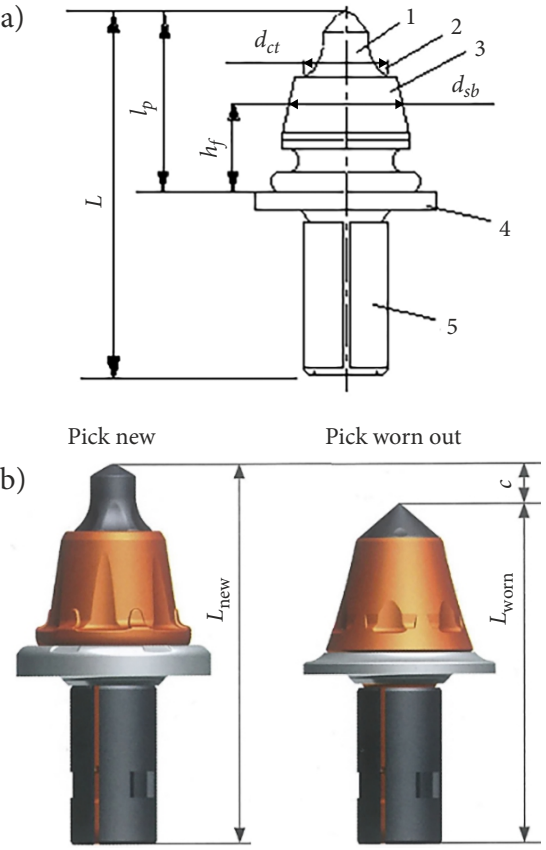

Figure 2. Pick of milling machine: a - scheme of measurement of GP and its elements ( 1 - carbide tip, 2 - brazing, 3 - steel body, 4 - wear plate, 5 - clamping sleeve); $\mathrm{b}$ - views of the new and optimally worn pick

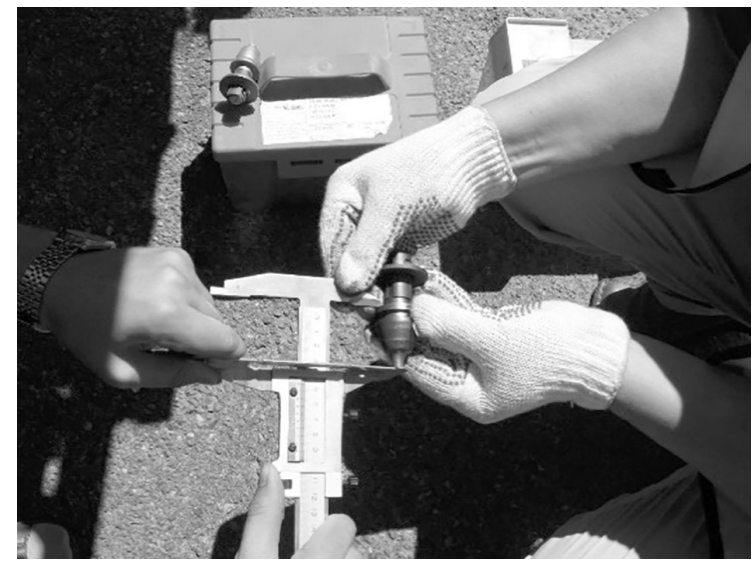

Figure 3. New pick's length $l_{p}$ measuring using calliper some areas with clearly visible transverse and longitudinal cracks and its thickness varied from 44 to $53 \mathrm{~mm}$. There is the traffic of heavy vehicles on this road and its owner decided to strengthen the road surface structure and improve its hydrothermal conditions. The entire layer of asphalt concrete with approximately $5 \mathrm{~cm}$ thickness and the unbound gravel and sand subbase layer in approximately $10 \mathrm{~cm}$ thickness was loosened by the milling machine. The materials of both layers were mixed with a milling machine to obtain a homogeneous layer as a mixture of RAP and crushed aggregate subbase in approximately $15 \mathrm{~cm}$ thickness, which was later compacted by single drum roller.

The condition of the pick was periodically monitored after the old road pavement was started to loosen. Improperly worn, dropped, or broken picks have been replaced with new ones and their number was captured. GP $l_{p}, d_{c t}$ and $d_{s b}$ of all picks were measured after milling $700 \mathrm{~m}^{2}$ (milled area $A$ ) of road pavement (approximately $35 \mathrm{~m}^{3}$ of asphalt concrete and $70 \mathrm{~m}^{3}$ of unbound aggregates). The improperly worn 2 picks (No 32 and 58) made by manufacturer $\mathrm{K}$ were replaced with new pick, which were not used in later study's steps. The pick wear was increasing even more further continuing the process of pavement loosening. After $1450 \mathrm{~m}^{2}$ of road pavement was milled (approximately $72.5 \mathrm{~m}^{3}$ of asphalt concrete and $145 \mathrm{~m}^{3}$ of unbound aggregates), the sizes of picks $l_{p}, d_{c t}$ and $d_{s b}$ were determined according to the same methodology. Another $\mathrm{K}$ manufacturer pick (No 52) and $2 \mathrm{~W}$ manufacturer picks (No 13 and 33) were found as improperly worn when the road pavement milling process was finished. The ambient air temperature was not assessed in this study, which was $17^{\circ} \mathrm{C}$ during milling of dry road pavement up to $700 \mathrm{~m}^{2}$ and $20^{\circ} \mathrm{C}$ during milling of the rest $1450 \mathrm{~m}^{2}$ pavement. Not all picks had worn optimally as it is shown in Figure $2 b$. The most common cases of undesired wear in practice are: steel body washing out; excessive wear to the wear plate; carbide breakage; excessive lengthwise wear; bad rotation and clamping sleeve wear. These specific cases of improper wear are determined by certain conditions. Specialists are aware of the cause and effect and the possible solution.

\section{Research results and discussion}

The reduction of the 3 GP: (1) length of pick, (2) diameter of carbide tip, (3) diameter of steel body - of picks from each manufacturer (W and $\mathrm{K}$ ) after the milling of the $700 \mathrm{~m}^{2}$ and $1450 \mathrm{~m}^{2}$ asphalt pavement is shown in Figure 4 . The degree of wear of individual pick from the same manufacturer differs due to stochastic factors and has a certain variation, which increases depending on the area $A$ of the dismantled asphalt pavement. The higher amount of the pavement is milled, the greater variation of the GP of the picks is.

2 forms of regression equations were chosen to determine the wear trend of the picks: the straight-line equation and the quadratic equation: 


$$
y=b \cdot x+a_{0}
$$

and

$$
y=c \cdot x^{2}+b \cdot x+a_{0},
$$

where: $y$ - pick GP $\left(l_{p}, d_{c t}\right.$ and $\left.d_{s b}\right)[\mathrm{mm}] ; a_{0}, b, c$ - the free members of the regression equation were determined by the least squares' method; $x$ - area of loosened asphalt pavement $A\left[\mathrm{~m}^{2}\right]$.

The values of the coefficient of determination $R^{2}$ in the Equation (8) are higher and this indicates that it better corresponds to the experimental data. Calculated $R^{2}$ values vary from 0.7254 to 0.8843 and indicates that picks wear from 72.5 to $88.4 \%$ depends on milled area $A$. Regression equation indicates that picks every GP decreases rapidly if milled area $A$ increases.

a)
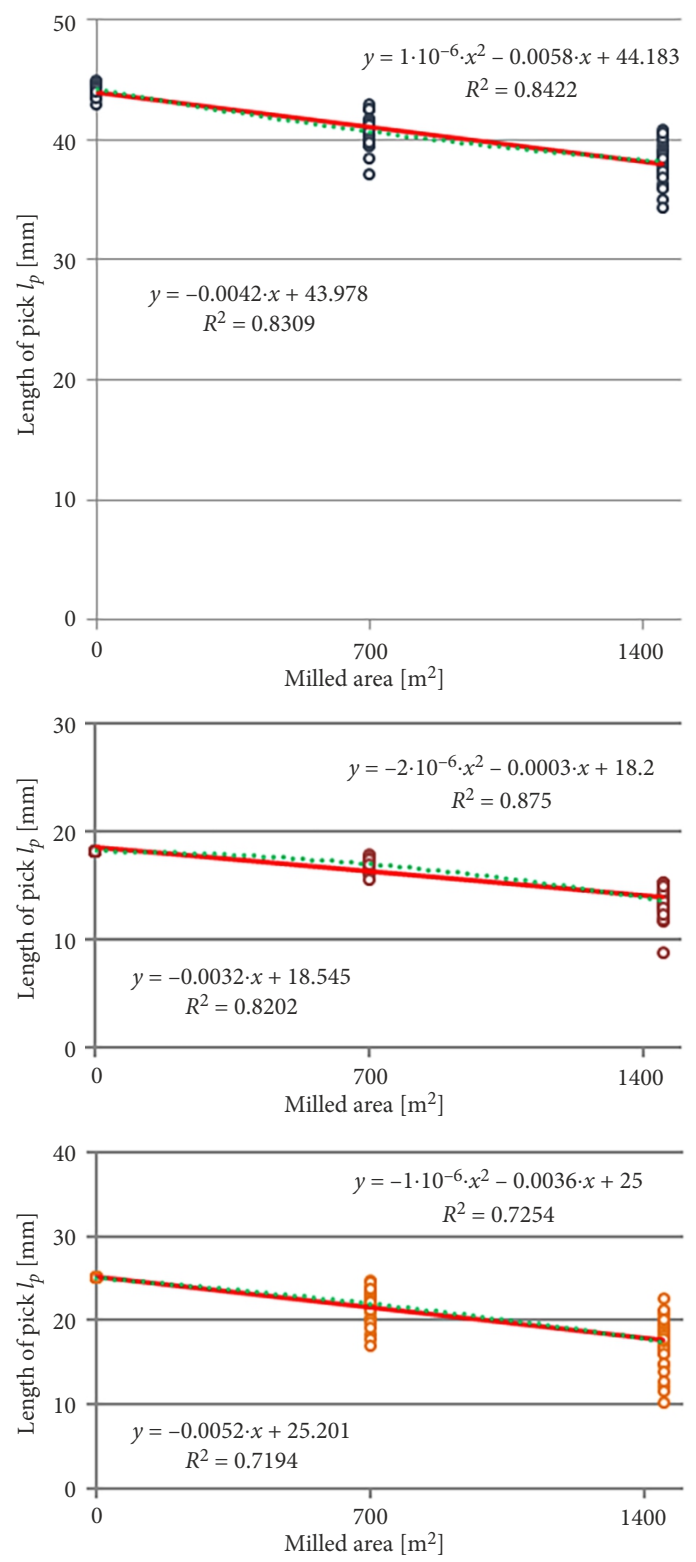

Picks GP statistical data (Tables 2, 3 and 4) indicates that they changed depending on milled area $A$ for pick of both manufacturers ( $\mathrm{W}$ and $\mathrm{K}$ ). The mean $\bar{y}$ and standard deviation $\sigma_{y}$, called position and dispersion characteristics respectively, were calculated for picks, which quantity $n_{\mathrm{W}}$ and $n_{\mathrm{K}}$ is given in Table 3. This quantity of picks was used to determine the correspondence of each GP variation to the normal distribution according to the Kolmogorov's criterion - Equation (5). Applying an extremely strict significance level of $\alpha=0.30$, the values calculated for 3 GPs out of 12 distributions were $\lambda$ greater than 0.974 at the recommended $\alpha=0.05$, with only one distribution $(\lambda=1.581)$ being greater than $\lambda_{\alpha}=1.358$. Therefore, it can reasonably be stated that the GPs of the picks are distributed according to the normal law, which allows the use

b)
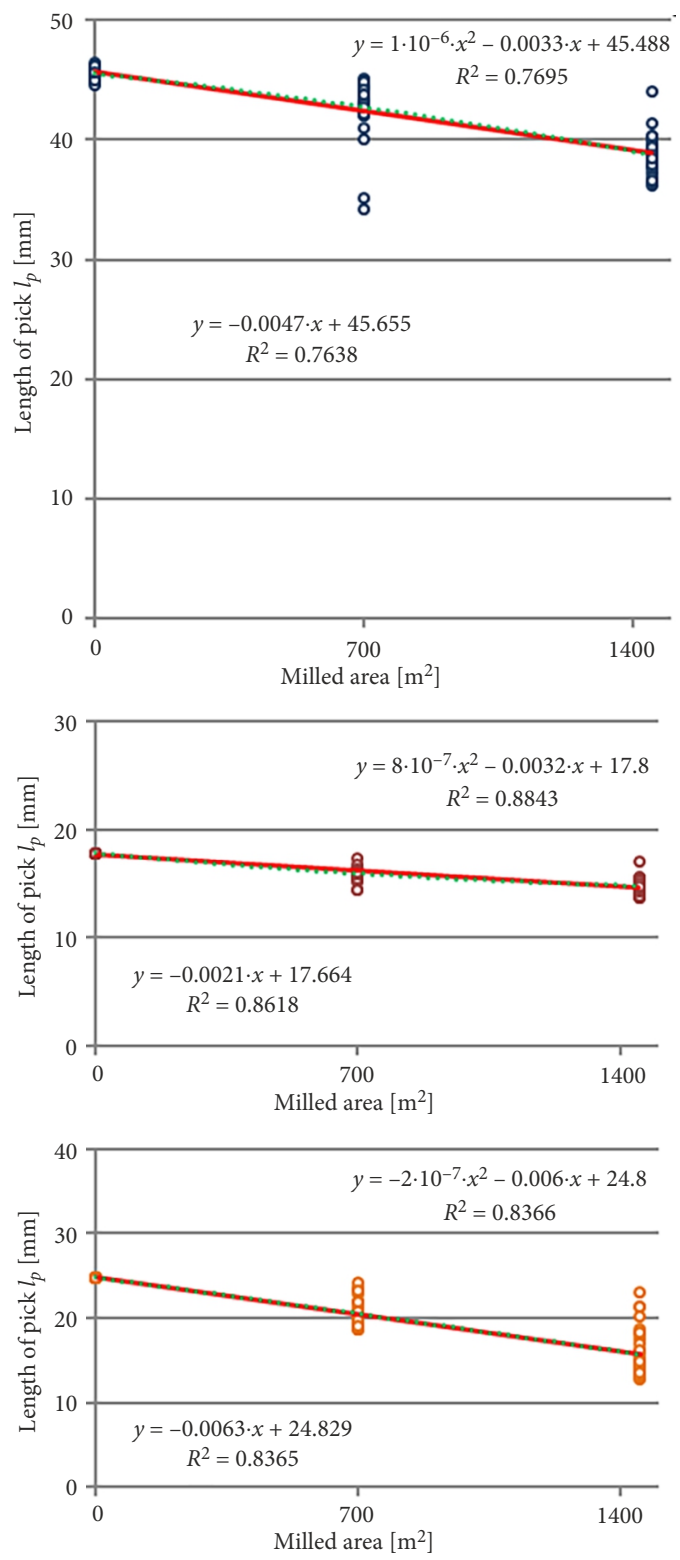

Figure 4. $3 \mathrm{GP}$ of milling machine picks decrease regression and variation diagram of experimental data without outliers: $\mathrm{a}$ - manufacturer $\mathrm{W}$; $\mathrm{b}$ - manufacturer $\mathrm{K}$ 
of Fisher's and Student's criterions for the comparison of statistical indicators and $\bar{y}$ and $\sigma_{y}$.

Length of pick $\bar{l}_{p}$ installed in the milling drum after the loosing of $700 \mathrm{~m}^{2}$ asphalt pavement more decreased by manufacturer $\mathrm{W}$ than by manufacturer $\mathrm{K}$ $\left(\Delta \bar{y}_{\mathrm{W}}=3.45 \mathrm{~mm} ; \Delta \bar{y}_{\mathrm{K}}=2.65 \mathrm{~mm}\right.$ ) (Table 4). K manufacturer's picks wore more than $\mathrm{W}$ manufacturer picks $\left(\Delta \bar{y}_{\mathrm{W}}=5.97 ; \Delta \bar{y}_{\mathrm{K}}=6.97 \mathrm{~mm}\right)$ after the milling of the $1450 \mathrm{~m}^{2}$ asphalt pavement.

Diameter of carbide tip $\bar{d}_{c t}$ more decreased for the picks of $\mathrm{K}$ manufacturer than $\mathrm{W}$ manufacturer $\left(\Delta \bar{y}_{\mathrm{W}}=1.23 \mathrm{~mm} ; \Delta \bar{y}_{\mathrm{K}}=1.94 \mathrm{~mm}\right)$ after $700 \mathrm{~m}^{2}$ asphalt pavement was milled. This GP $\left(\bar{d}_{c t}\right)$ more decreased for the pick of manufacturer $\mathrm{W}$ than $\mathrm{K}$ manufacturer $\left(\Delta \bar{y}_{\mathrm{W}}=4.69 \mathrm{~mm} ; \Delta \bar{y}_{\mathrm{K}}=3.03 \mathrm{~mm}\right)$ after $1450 \mathrm{~m}^{2}$ asphalt pavement was milled, i.e., the opposite trend than the reduction in the length of the picks.

Diameter of steel body $\bar{d}_{s b}$ more decreased for the picks of K manufacturer $\left(\Delta \bar{y}_{\mathrm{K}}=4.28 \mathrm{~mm} ; \Delta \bar{y}_{\mathrm{K}}=9.19 \mathrm{~mm}\right)$ after $700 \mathrm{~m}^{2}$ and $1450 \mathrm{~m}^{2}$ asphalt pavement was milled. $\mathrm{W}$ manufacturer picks' $\bar{d}_{s b}$ after $700 \mathrm{~m}^{2}$ pavement milling was $\Delta \bar{y}_{\mathrm{W}}=3.13 \mathrm{~mm}$ and respectively $\Delta \bar{y}_{\mathrm{W}}=7.58 \mathrm{~mm}$ after $1450 \mathrm{~m}^{2}$ according experimental data.

As testing the null hypothesis $H_{0}$, which states that there is no significant difference between the comparative parameters (pick wear rate) statistics (GP decrease), the

Table 2. Comparison of statistical data wear of the picks of cold milling machine after milling of old asphalt concrete pavement

\begin{tabular}{|c|c|c|c|c|c|c|c|}
\hline \multirow{3}{*}{ The picks GP [mm] } & \multirow{3}{*}{$\begin{array}{c}\text { Company } \\
\text { abbreviation }\end{array}$} & \multicolumn{6}{|c|}{ Milled area $A\left[\mathrm{~m}^{2}\right]$} \\
\hline & & \multicolumn{2}{|r|}{0 (new picks) } & \multicolumn{2}{|r|}{700} & \multicolumn{2}{|r|}{1450} \\
\hline & & mean & standard deviation & mean & standard deviation & mean & standard deviation \\
\hline \multirow{2}{*}{ Length of pick } & W & 44.18 & 0.379 & 40.73 & 1.167 & 38.21 & 1.466 \\
\hline & $\mathrm{K}$ & 45.50 & 0.497 & 42.85 & 1.743 & 38.53 & 1.472 \\
\hline \multirow{2}{*}{ Diameter of carbide tip } & $\mathrm{W}$ & 18.20 & - & 16.97 & 0.430 & 13.51 & 1.197 \\
\hline & $\mathrm{K}$ & 17.80 & - & 15.86 & 0.499 & 14.77 & 0.645 \\
\hline \multirow{2}{*}{ Diameter of steel body } & W & 25.0 & - & 21.87 & 1.730 & 17.42 & 2.870 \\
\hline & $\mathrm{K}$ & 24.8 & - & 20.52 & 1.440 & 15.61 & 2.508 \\
\hline
\end{tabular}

Table 3. The quantity of picks used in the study and the distribution of their dimensional normality according to the Kolmogorov's criterion ( $\lambda$ value)

\begin{tabular}{|l|c|c|c|c|}
\hline \multirow{2}{*}{ The picks GP $[\mathrm{mm}]$} & \multirow{2}{*}{$\begin{array}{c}\text { Company } \\
\text { abbreviation }\end{array}$} & 0 (new picks) & 700 & \multicolumn{3}{|c|}{ Milled area $A\left[\mathrm{~m}^{2}\right]$} \\
\cline { 3 - 5 } & & $40(0.410)$ & $39(0.488)$ & $37(0.341)$ \\
\hline \multirow{2}{*}{ Length of pick } & $\mathrm{W}$ & $40(0.850)$ & $38(1.278)$ & $36(0.633)$ \\
\cline { 2 - 5 } & $\mathrm{K}$ & $40(-)$ & $39(0.460)$ & $37(0.404)$ \\
\hline \multirow{2}{*}{ Diameter of carbide tip } & $\mathrm{W}$ & $40(-)$ & $37(0.895)$ & $36(0.471)$ \\
\hline \multirow{2}{*}{ Diameter of steel body } & $\mathrm{K}$ & $40(-)$ & $39(1.105)$ & $37(0.350)$ \\
\cline { 2 - 5 } & $\mathrm{W}$ & $40(-)$ & $38(0.685)$ & $36(1.581)$ \\
\hline
\end{tabular}

Table 4. Data and evaluation of the wear uniformity test of 2 manufacturers of picks according to Fisher's and Student's criteria

\begin{tabular}{|c|c|c|c|c|c|c|c|c|c|}
\hline \multirow{4}{*}{$\begin{array}{c}\text { The picks GP } \\
{[\mathrm{mm}]}\end{array}$} & \multirow{4}{*}{$\begin{array}{c}\text { Milled } \\
\text { area } A \\
{\left[\mathrm{~m}^{2}\right]}\end{array}$} & \multirow{2}{*}{\multicolumn{2}{|c|}{$\begin{array}{l}\text { The difference } \\
\text { between the new } \\
\text { and worn pick } \\
\text { mean values [mm] }\end{array}$}} & \multicolumn{4}{|c|}{ Statistic value } & \multirow{2}{*}{\multicolumn{2}{|c|}{$\begin{array}{l}\text { Conclusion about } \\
\text { null hypothesis }\end{array}$}} \\
\hline & & & & \multicolumn{2}{|c|}{ Fisher's criterion } & \multicolumn{2}{|c|}{ Student's criterion } & & \\
\hline & & \multirow[b]{2}{*}{$\Delta \bar{y}_{\mathrm{W}}$} & \multirow[b]{2}{*}{$\Delta \bar{y}_{\mathrm{K}}$} & calculated & critical & calculated & critical & \multirow[b]{2}{*}{ Fisher } & \multirow[b]{2}{*}{ Student } \\
\hline & & & & $F_{c a}$ & $\begin{array}{c}F_{c r}(0.05 \\
\left.n_{\mathrm{W}} ; n_{\mathrm{K}}\right)\end{array}$ & $t_{c a}$ & $\begin{array}{c}t_{c r} \\
n^{\prime}=n_{\mathrm{W}}+n_{\mathrm{K}}-2\end{array}$ & & \\
\hline \multirow{2}{*}{ Length of pick } & 700 & 3.45 & 2.65 & 1.49 & 1.66 & 2.91 & $1.99 ; 1.67$ & + & - \\
\hline & 1450 & 5.97 & 6.97 & 1.00 & 1.71 & 3.52 & $1.99 ; 1.67$ & + & - \\
\hline \multirow{2}{*}{$\begin{array}{l}\text { Diameter of } \\
\text { carbide tip }\end{array}$} & 700 & 1.23 & 1.94 & 1.16 & 1.67 & 4.54 & $1.99 ; 1.67$ & + & - \\
\hline & 1450 & 4.69 & 3.03 & 1.86 & 1.71 & 7.37 & $1.99 ; 1.67$ & - & - \\
\hline \multirow{2}{*}{$\begin{array}{l}\text { Diameter of } \\
\text { steel body }\end{array}$} & 700 & 3.13 & 4.28 & 1.20 & 1.67 & 4.00 & $1.99 ; 1.67$ & + & - \\
\hline & 1450 & 7.58 & 9.19 & 1.14 & 1.71 & 4.71 & $1.99 ; 1.67$ & + & - \\
\hline
\end{tabular}

Notes: a "+" sign indicates that the null hypothesis about the uniformity of the pick GP is accepted; a "_" sign indicates that the hypothesis is rejected. 
uniformity of each GP variances $\sigma_{\mathrm{W}}^{2}$ and $\sigma_{\mathrm{K}}^{2}$ were initially determined according to Fisher's criterion. The empirical values of the statistics $F_{c a}$ calculated according to Equation (3) are given in Table 4. Comparing them with the critical values of $F_{c r}$ depending on the significance level $\alpha=0.05$ and the number of picks $n_{\mathrm{W}}$ ir $n_{\mathrm{K}}$, it can be stated that only the variances of the diameter carbide tip $\sigma_{\mathrm{W}}^{2}$ and $\sigma_{\mathrm{K}}^{2}$, were not statistically equal because $F_{c a}>F_{c r}$ $(1.86>1.71)$. The reduction variances of the other GPs $\sigma_{\mathrm{W}}^{2}$ and $\sigma_{\mathrm{K}}^{2}$ of the pick of both manufacturers (W and K) (Table 2) were the same because $F_{c a}<F_{c r}$ (Table 4).

After proving that the investigated values (pick wear) are independent and distributed according to the normal law and their variances are equal, it is examined according to Student's criterion whether the mean reductions $\Delta \bar{y}$ of 3 GPs of 2 manufacturers (W and $\mathrm{K}$ ) are significantly different (Equation (1)). The results (Table 4) indicates that the calculated $t_{c a}$ of the $3 \mathrm{GPs}$ are greater than their critical values $t_{c r}$. Therefore, it can reasonably be argued that

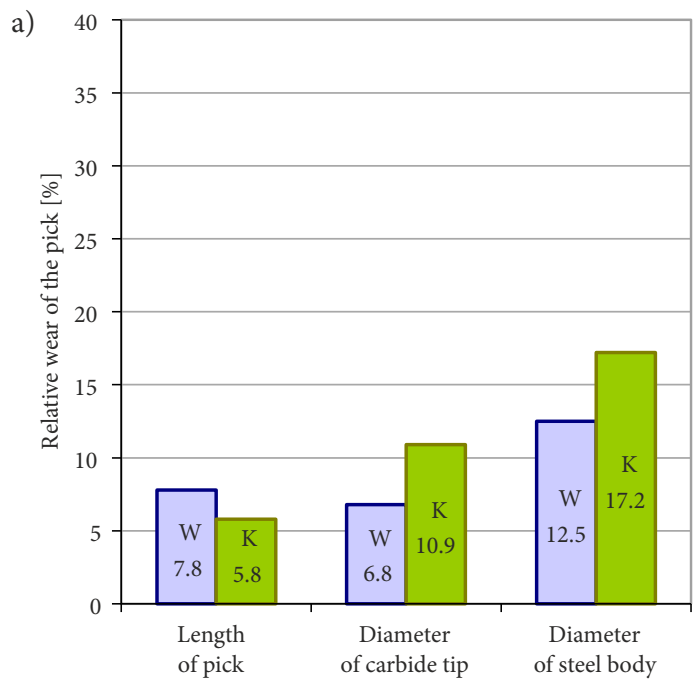

the pick wear of both manufacturers acts with different intensities.

The relative decrease in GP of the picks of individual manufacturers (W and K) calculated by Equation (6) differs (Figure 5). The pick length from the manufacturer $\mathrm{W}$ decreased more intensively $(\varepsilon=7.8 \%)$ milling asphalt pavement up to $700 \mathrm{~m}^{2}$ and the diameter of the carbide tip of this manufacturer's picks decreased more intensively $(\varepsilon=25.8 \%)$ at the end of the milling process, i.e., after $1450 \mathrm{~m}^{2}$. Throughout the complete pavement milling cycle (up to $1450 \mathrm{~m}^{2}$ ) the steel body wear of the $\mathrm{K}$ manufacturer's pick was faster $(\varepsilon=17.2 \%$ and $\varepsilon=37.1 \%)$. These experimental data indicate that no pick manufacturer has a clear priority in terms of the reduction in pick length and carbide tip diameter.

The average values of the relative decrease $\bar{\varepsilon}$ in GP $\left(l_{p}\right.$, $d_{c t}$ and $d_{s b}$ ) of each manufacturer's pick calculated from the data of the diagrams (Figure 5) are almost the same. After the milling of $700 \mathrm{~m}^{2}$ of asphalt pavement using W

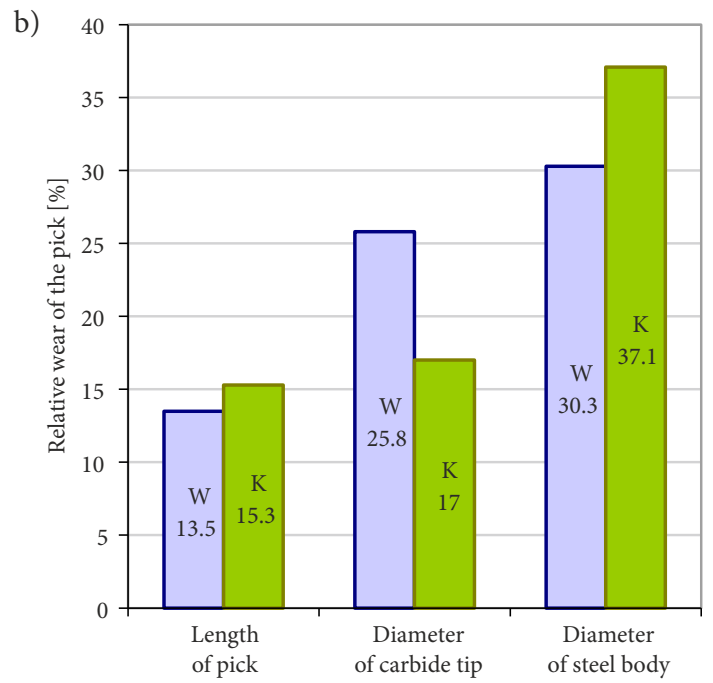

Figure 5. Relative wear $\varepsilon$ of $\mathrm{W}$ and $\mathrm{K}$ pick after milling of asphalt pavement: $\mathrm{a}-700 \mathrm{~m}^{2}, \mathrm{~b}-1450 \mathrm{~m}^{2}$

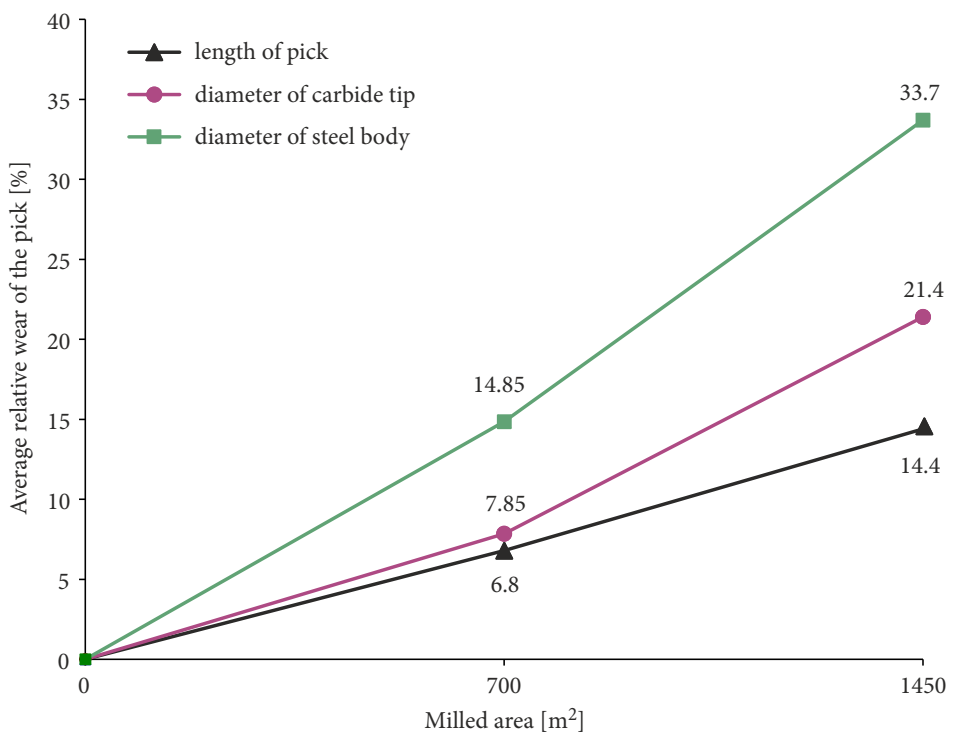

Figure 6. The average decrease of pick GP of 2 manufacturers milling asphalt pavement 
manufacturers' picks, their 3 GPs were reduced by an average of:

$$
\bar{\varepsilon}_{\mathrm{W}}=\left(\varepsilon_{l_{p}}+\varepsilon_{d_{c t}}+\varepsilon_{d_{s b}}\right): 3=(7.8+6.8+12.5): 3=9.0 \%,
$$

and the $\mathrm{K}$ by $\bar{\varepsilon}_{\mathrm{K}}=11.3 \%$. After the milling of the $1450 \mathrm{~m}^{2}$ asphalt pavement, the GP of the picks of manufacturer $\mathrm{W}$ decreased on average by $\bar{\varepsilon}_{\mathrm{W}}=23.2 \%$ and that for manufacturer $\mathrm{K}$ by $\bar{\varepsilon}_{\mathrm{K}}=23.1 \%$, i.e., worn out equally.

The length $l_{p}$ of the picks of both manufacturers decreased on average by $6.8 \%$ after the milling of $700 \mathrm{~m}^{2}$ of asphalt pavement and $14.4 \%$ after milling $1450 \mathrm{~m}^{2}$. The diameter of the carbide tip $\bar{d}_{c t}$ decreased on average by $8.85 \%$ and $21.4 \%$ respectively and the diameter of the steel body $\bar{d}_{s b}$ by $14.85 \%$ and $33.7 \%$ respectively (Figure 6). The pick length wear was slowest, and the diameter of the steel body wear was the fastest.

Field experiment was performed with the same model road milling machine when the asphalt pavement was milled in 2 layers with thickness of 160 and $100 \mathrm{~mm}$ accordingly. Picks of larger dimensions from 2 manufacturers were used during this trial. The results indicated that the relative reduction in the length of the picks was uniform and the reduction of the diameter of the carbide tip of manufacturer $\mathrm{K}$ was $4 \%$ higher than manufacturer $\mathrm{W}$.

Another experiment was provided milling $200 \mathrm{~mm}$ thickness asphalt pavement layer in milling in all depth and milling in 2 layers of $100+100 \mathrm{~mm}$. Picks' lifetime was longer milling in 2 thicker layers than milling in one pass.

\section{Conclusions}

»» during the interaction of the milling machine's picks with the material of the old asphalt pavement its layer is broken at a certain depth into the grains as RAP granulate, suitable for recycling in cold and hot conditions. During the cold milling process the picks wear out and the GP of their elements are reduced. Reducing the wear rate (intensity) of the picks would have the economic effect of asphalt recycling technology, thus allowing the road construction company to compete successfully in business;

"» the presented model of determination and evaluation of the wear process of 2 different manufacturers picks allows to compare the intensity of the decrease of their GP with the growing amount of the milled asphalt pavement area. Using the Student's criterion, the values of each change (decrease) in GP distributed according to the normal law are compared when their variances are equal, and the samples are independent. The uniformity of the variances (consistency of the null hypothesis) is determined using the Fisher's criterion and the normality of the variation of the pick wear data is determined according to the Kolmogorov's criterion. The relative percentage reduction of GP of the picks was used to estimate the wear rate of each element;
"» during field experiments equal wear conditions were created for 40 picks installed in milling drum toolholders from 2 different manufacturers ( $\mathrm{W}$ and $\mathrm{K}$ ) to determine the length of the picks, the diameter of the carbide tip and the diameter of the steel body reduction. In order to, all picks were measured before milling approximately $5 \mathrm{~cm}$ thickness asphalt pavement of 700 and $1450 \mathrm{~m}^{2}$ area according to the chosen milling technology and mixing it in-situ with a unbound aggregates base layer approximately $10 \mathrm{~cm}$ thick, seeking to determine and statistically evaluate their wear intensity;

"'» as the area of the milled asphalt pavement increases, all GPs of the picks decrease according to the square regression equation and the variation in the dimensions of their elements increases. The difference between the dimension of the new and worn pick element is used to estimate the wear intensity of the pick. A comparative analysis of the GP reduction of the individual elements of the picks from both manufacturers $(\mathrm{W}$ and $\mathrm{K}$ ) indicates that with the selected significance level $\alpha=0.05$ according to the calculated values of Student's $t$-statistic, they wear is with different intensities. The arithmetic means of the relative percentage reduction of the 3 GPs of the picks from manufacturers $\mathrm{W}$ and $\mathrm{K}$ indicated that no significant difference was found in the complex assessment of their wear rate. The values of the wear intensity of the picks may be different due to changes in the milling conditions of the pavement (asphalt composition and performance, layer thickness, ambient temperature, milling machine and drum movement parameters, etc.). The results of this study indicate a trend in the wear of the picks and are not absolute recommended for practical use; "») objective identification of geometrical picks wear allows to start of creation milling costs methodology, which could be effectively adopted for road pavement maintenance operators and owners. This field investigation and results would be a basis for the further development of milling machine pick wear determination including pavement composition, weather conditions.

\section{References}

AI. 1986. Asphalt Hot-Mix Recycling. Manual Series No 20 (MS20). Asphalt Institute (AI), College Park, MD, US. 46 p.

Akbarian, M.; Moeini-Ardakani, S. S.; Ulm, F.-J. Nazzal, M. 2012. Mechanistic approach to pavement-vehicle interaction and its impact on life-cycle assessment, Transportation Research Record: Journal of the Transportation Research Board 2306: 171-179. https://doi.org/10.3141/2306-20

Amini, B.; Tehrani, S. S. 2014. Simultaneous effects of salted water and water flow on asphalt concrete pavement deterioration under freeze-thaw cycles, International Journal of Pavement Engineering 15(5): 383-391.

https://doi.org/10.1080/10298436.2012.677844 
Anyala, M.; Odoki, J. B.; Baker, C. J. 2014. Hierarchical asphalt pavement deterioration model for climate impact studies, International Journal of Pavement Engineering 15(3): 251-266. https://doi.org/10.1080/10298436.2012.687105

Ceylan, H.; Gopalakrishnan, K.; Lytton, R. L. 2011. Neural networks modeling of stress growth in asphalt overlays due to load and thermal effects during reflection cracking, Journal of Materials in Civil Engineering 23(3): 221-229. https://doi.org/10.1061/(ASCE)MT.1943-5533.0000153

Cui, Y.; Glover, C. J.; Braziunas, J.; Sivilevicius, H. 2018. Further exploration of the pavement oxidation model - diffusion-reaction balance in asphalt, Construction and Building Materials 161: 132-140. https://doi.org/10.1016/j.conbuildmat.2017.11.095

Farhan, J.; Fwa, T. F. 2009. Pavement maintenance prioritization using analytic hierarchy process, Transportation Research Record: Journal of the Transportation Research Board 2093: 12-24. https://doi.org/10.3141/2093-02

Furmanov, D.; Chizhov, V.; Tyuremnov, I.; Troshin, D. 2019. Loads on cutter teeth for removing asphalt pavement, E3S Web of Conferences 97: 06031.

https://doi.org/10.1051/e3sconf/20199706031

Gu, H.-R.; Jiao, S.-J.; Xiao C.-Y.; Wang, F.-C.; Lin, T. 2012. Analysis and test on asphalt milling machine cutting load characteristic, China Journal of Highway and Transport 25(3): 154158. https://doi.org/10.19721/j.cnki.1001-7372.2012.03.018 (in Chinese).

Harun-Or-Rashid, G. M.; Ahmed, B.; Sobhan, M. A.; Rahman, N. 2018. Marshall characteristics of bituminous mixes using reclaimed asphalt pavement, American Journal of Traffic and Transportation Engineering 3(4): 57-61.

Hossain, M. I.; Veginati, V.; Krukow, J. 2015. Thermodynamics Between RAP/RAS and Virgin Aggregates During Asphalt Concrete Production - a Literature Review. Federal Highway Administration, Washington, DC, US. 79 p.

Iovanas, D. M.; Dumitrascu, A.-E. 2017. Reliability estimation of the milling machines teeth obtained by welding deposition process, MATEC Web of Conferences 121: 02003.

https://doi.org/10.1051/matecconf/201712102003

Khattak, M. J.; Nur, M. A.; Bhuyan, M. R.-U-K.; Gaspard, K. 2014. International roughness index models for HMA overlay treatment of flexible and composite pavements, International Journal of Pavement Engineering 15(4): 334-344. https://doi.org/10.1080/10298436.2013.842237

Kleizienė, R.; Panasenkienè, M.; Vaitkus, A. 2019. Effect of aging on chemical composition and rheological properties of neat and modified bitumen, Materials 12(24): 4066.

https://doi.org/10.3390/ma12244066

Kremer, N. S. 2012. Teorija verojatnostej $i$ matematicheskaja statistika. Moskva: JuNITI. 550 s. (in Russian).

Kubo, P.; Paiva, C.; Larocca, A.; Dawson, J. 2016. Quantification of the vertical load applied to the pavement during braking maneuver of a commercial vehicle, Journal of Transportation Engineering 142(4): 06016001.

https://doi.org/10.1061/(ASCE)TE.1943-5436.0000834

Liu, H.; Hao, P.; Wang, H.; Adhikair, S. 2014. Effects of physiochemical factors on asphalt aging behavior, Journal of Materials in Civil Engineering 26(1): 190-197.

https://doi.org/10.1061/(ASCE)MT.1943-5533.0000786

Ma, T.; Huang, X.; Zhao, Y.; Yuan, H.; Ma, X. 2012. Degradation behavior and mechanism of HMA aggregate, Journal of Testing and Evaluation 40(5): 697-707.

Mansourkhaki, A.; Sarkar, A.; Ameri, M. 2015. Impact of different loading patterns with short duration on the permanent strain of asphalt mixture, Journal of Testing and Evaluation 43(4): 853-866.

Meagher, W.; Daniel, J. S.; Jacobs, J.; Linder, E. 2012. Method for evaluating implications of climate change for design and performance of flexible pavements, Transportation Research Record: Journal of the Transportation Research Board 2305: 111-120. https://doi.org/10.3141/2305-12

NAPA. 1996. Recycling Hot Mix Asphalt Pavements. Information Series 123. National Asphalt Pavement Association (NAPA), Lanham, MD, US. 28 p.

NCHRP. 2011. A Manual for Design of Hot-Mix Asphalt with Commentary. NCHRP Report 673. National Cooperative Highway Research Program (NCHRP), Washington, DC, US. 273 p. https://doi.org/10.17226/14524

Nguyen, H. V. 2013. Effects of mixing procedures and rap sizes on stiffness distribution of hot recycled asphalt mixtures, Construction and Building Materials 47: 728-742. https://doi.org/10.1016/j.conbuildmat.2013.05.056

Papagiannakis, A. T.; Masad, E. A. 2008. Pavement Design and Materials. John Wiley \& Sons, Inc. 560 p. https://doi.org/10.1002/9780470259924

Plati, C.; Cliatt, B. 2019. A sustainability perspective for unbound reclaimed asphalt pavement (rap) as a pavement base material, Sustainability 11(1): 78.

https://doi.org/10.3390/su11010078

Puccini, M.; Leandri, P.; Tasca, A.L.; Pistonesi, L.; Losa, M. 2019. Improving the environmental sustainability of low noise pavements: comparative life cycle assessment of reclaimed asphalt and crumb rubber based warm mix technologies, Coatings 9(5): 343. https://doi.org/10.3390/coatings 9050343

Ržek, L.; Turk, M. R.; Tušar, M. 2020. Increasing the rate of reclaimed asphalt in asphalt mixture by using alternative rejuvenator produced by tire pyrolysis, Construction and Building Materials 232: 117177.

https://doi.org/10.1016/j.conbuildmat.2019.117177

Salour, F.; Erlingsson, S. 2013. Moisture-sensitive and stressdependent behavior of unbound pavement materials from in situ falling weight deflectometer tests, Transportation Research Record: Journal of the Transportation Research Board 2335: 121-129. https://doi.org/10.3141/2335-13

Shirodkar, P.; Mehta, Y.; Nolan, A.; Sonpal, K.; Norton, A.; Tomlinson, C.; Dubois, E.; Sullivan, P.; Sauber, R. 2011. A study to determine the degree of partial blending of reclaimed asphalt pavement (RAP) binder for high RAP hot mix asphalt, Construction and Building Materials 25(1): 150-155.

https://doi.org/10.1016/j.conbuildmat.2010.06.045

Sivilevičius, H.; Bražiūnas, J.; Prentkovskis, O. 2017. Technologies and principles of hot recycling and investigation of preheated reclaimed asphalt pavement batching process in an asphalt mixing plant, Applied Sciences 7(11): 1104.

https://doi.org/10.3390/app7111104

Sivilevičius, H.; Vislavičius, K. 2019. Simulation of composition of recycled hot-mix asphalt mixture produced in asphalt mixing plant, Construction and Building Materials 214: 17-27. https://doi.org/10.1016/j.conbuildmat.2019.03.330

Solatifar, N.; Abbasghorbani, M.; Kavussi, A.; Sivilevičius, H. 2018. Prediction of depth temperature of asphalt layers in hot climate areas, Journal of Civil Engineering and Management 24(7): 516-525. https://doi.org/10.3846/jcem.2018.6162

Solatifar, N.; Kavussi, A.; Abbasghorbani, M.; Sivilevičius, H. 2017. Application of FWD data in developing dynamic modulus master curves of in-service asphalt layers, Journal of Civil Engineering and Management 23(5): 661-671. https://doi.org/10.3846/13923730.2017.1292948 
Toh, C. K. 2005. Design, evaluation and optimisation of cutter path strategies when high speed machining hardened mould and die materials, Materials \& Design 26(6): 517-533.

https://doi.org/10.1016/j.matdes.2004.07.019

Vislavičius, K.; Sivilevičius, H. 2013. Effect of reclaimed asphalt pavement gradation variation on the homogeneity of recycled hot-mix asphalt, Archives of Civil and Mechanical Engineering 13(3): 345-353. https://doi.org/10.1016/j.acme.2013.03.003

Wang, F.; Zhang, L.; Yan, B.; Kong, D.; Li, Y.; Wu, S. 2019. Diffusion mechanism of rejuvenator and its effects on the physical and rheological performance of aged asphalt binder, Materials 12(24): 4130. https://doi.org/10.3390/ma12244130

Wirtgen Group. 2016. Picks. Available from Internet: https://www.wirtgen-group.com

Wirtgen Group. 2019. WIRTGEN Cold Milling Manual. Technology and Application. $280 \mathrm{p}$.

Wu, S.; Qiu, J.; Mo, L.; Yu, J.; Zhang, Y.; Li, B. 2007. Investigation of temperature characteristics of recycled hot mix asphalt mixtures, Resources, Conservation and Recycling 51(3): 610-620. https://doi.org/10.1016/j.resconrec.2006.11.005

Zaumanis, M.; Boesiger, L.; Kunz, B.; Cavalli, M. C. Poulikakos, L. 2019. Determining optimum rejuvenator addition location in asphalt production plant, Construction and Building Materials 198: 368-378.

https://doi.org/10.1016/j.conbuildmat.2018.11.239

Zaumanis, M.; Cavalli, M. C.; Poulikakos, L. D. 2020. Effect of rejuvenator addition location in plant on mechanical and chemical properties of RAP binder, International Journal of Pavement Engineering 21(4): 507-515. https://doi.org/10.1080/10298436.2018.1492133

Zaumanis, M.; Mallick, R. B.; Frank, R. 2014a. 100\% recycled hot mix asphalt: a review and analysis, Resources, Conservation and Recycling 92: 230-245. https://doi.org/10.1016/j.resconrec.2014.07.007

Zaumanis, M.; Mallick, R. B.; Poulikakos, L.; Frank, R. 2014b. Influence of six rejuvenators on the performance properties of reclaimed asphalt pavement (RAP) binder and 100\% recycled asphalt mixtures, Construction and Building Materials 71: 538-550. https://doi.org/10.1016/j.conbuildmat.2014.08.073

Zhang, K.; Huchet, F.; Hobbs, A. 2019. A review of thermal processes in the production and their influences on performance of asphalt mixtures with reclaimed asphalt pavement (RAP), Construction and Building Materials 206: 609-619. https://doi.org/10.1016/j.conbuildmat.2019.02.057

Zofka, A.; Josen, R.; Paliukaite, M.; Vaitkus, A.; Mechowski, T.; Maliszewski, M. 2014. Elements of pavement management system: case study, The Baltic Journal of Road and Bridge Engineering 9(1): 1-9. https://doi.org/10.3846/bjrbe.2014.01 